\title{
MULTIPLE REGRESSION ANALYSIS BETWEEN THE MECHANICAL AND PHYSICAL PROPERTIES OF COHESIVE SOILS
}

\author{
Shigeyoshi Hirata ${ }^{\mathrm{i})}$, Shintaro $\mathrm{YaO}^{\mathrm{ii})}$ and Kazuhiko Nishida ${ }^{\mathrm{iii})}$
}

\begin{abstract}
In order to accurately determine the relationships between a mechanical property and some physical properties in both natural and artificially mixed cohesive soils, multiple regression analysis was performed. In this paper, two kinds of regression models representing the shear strength of soils are examined. The first model is based on the Atterberg limit and the second is based on the Cam-Clay model. The concept of this study is that the mechanical properties of the soils are characterized by soil types and soil states. The following conclusions were obtained: (1) Both regression models established for the shear strength of soils are not only found to be valid for the unconfined compressive strength, but also for the modulus of deformation and consolidation yield stress. (2) The validity of the concept employed here can be quantitatively proved by multiple regression analysis. (3) In a fully saturated soil, the correlation between the two regression models can be found both by statistical analysis and by theoretical examination. (4) The regression equations are obtained in good predictive accuracy for unconfined compressive strength, the modulus of deformation, consolidation yield stress and compression index.
\end{abstract}

Key words : cohesive soil, density, fully saturated soil, sensitivity, shear strength, soli structure, statistical analysis, unconfined compression test, water content (IGC: D3/D6/D0)

\section{INTRODUCTION}

The results of soundings in the site or of mechanical property tests of soil samples in the laboratory can be applied directly to foundation design. On the other hand, the results of physical property tests of soil samples can be easily obtained in the laboratory and play a role of supplement for soundings or mechanical property tests. If the relationships between a mechanical and a physical property become clear, it is so useful and important. Several studies have been done on this problem as follows: the relationships between shear strength and liquidity index (Ohsaki, 1961; Mikasa, 1967), those between internal friction angle and plasticity index (Bjerrum and Simons, 1960), those between sensitivity ratio

i) Technical Research Institute, Daiwa House Industry Co., Ltd., Saikujyo, Nara.

ii) Professor, Department of Architectural Engineering, Kansai University, Yamate, Suita, Osaka.

iii) Professor, Department of Civil Engineering, Kansai University, Yamate, Suita, Osaka. Manuscript was received for review on August 21, 1989.

Written discussions on this paper should be submitted before April 1, 1991, to the Japanese Society of Soil Mechanics and Foundation Engineering, Sugayama Bldg. 4 F, Kanda Awaji-cho 2-23, Chiyodaku, Tokyo 101, Japan. Upon request the closing date may be extended one month. 
and liquidity index (Skempton, 1953; Bjerrum, 1954), those between compression index and liquid limit (Skempton, 1944).

But these relationships would be limited in their application to foundation design, because of the following two reasons: (1) These relationships can not be explained in the necessary and sufficient conditions that the mechanical properties are generally characterized by both the soil types and states. (2) These relationships are not expressed together with the predictive accuracies that are needed for the designers to estimate a safety factor in foundation design.

In this paper, multiple regression analysis is used to attempt to accurately determine the relationships between a mechanical property and some major physical properties in cohesive soils. The data from both natural soils and artificially mixed soils, of which the clay content was more than 20\%, was analyzed statistically. The following points were the purposes in the analysis:

(1) To establish reasonable regression models of cohesive soils, before the analysis.

(2) To determine the regression equations expressing the relationship between a mechanical property and some physical properties of soils.

(3) To examine the contributions (partial correlation coefficient) of physical properties to a mechanical property.

(4) To examine the influencing relationships ( $F$-values) between each physical property.
(5) To determine the predictive accuracies (multiple correlation coefficient) of regression equations obtained from the analysis.

\section{CONCEPT AND METHOD OF ANALYSIS}

Multiple regression analysis was adopted to obtain the relationships between a mechanical property and some major physical properties on both natural soils and artificially mixed soils. Mechanical properties are given as dependent variables in Table 1, physical properties are given as independent variables in Table 2.

\section{Regression Models}

Mechanical properties are characterized generally by soil types and states (Mikasa, $1964,1967)$ as shown by the following function $F$ of Eq. (1).

Table 2. Physical properties as independent variables

\begin{tabular}{l|ll}
\hline \multirow{2}{*}{ soil type } & \multicolumn{2}{|c}{ physical property } \\
& clay content & $C(\%)$ \\
& silt content & $M_{0}(\%)$ \\
& sand content & $S(\%)$ \\
& liquid limit & $w_{L}(\%)$ \\
& plastic limit & $w_{p}(\%)$ \\
& plasticity index & $I_{p}(\%)$ \\
& plasticity ratio & $P_{r}$ \\
\hline \multirow{2}{*}{ density } & unit weight & $r_{t}\left(\mathrm{gf} / \mathrm{cm}^{3}\right)$ \\
& void ratio & $e$ \\
\hline \multirow{2}{*}{ water content } & water content & $w \quad(\%)$ \\
& degree of saturation & $S_{r}(\%)$ \\
& liquidity index & $I_{L}$ \\
\hline
\end{tabular}

Table 1. Mechanical properties as dependent variables

\begin{tabular}{|c|c|c|c|c|}
\hline & mechanical property & & nat. soil & art. soil \\
\hline \multirow[t]{2}{*}{ strength } & $\begin{array}{l}\text { unconfined compressive strength } \\
\text { remolded strength }\end{array}$ & $\begin{array}{ll}q_{u} & \left(\mathrm{kgf} / \mathrm{cm}^{2}\right) \\
q_{u r} & \left(\mathrm{kgf} / \mathrm{cm}^{2}\right)\end{array}$ & $\begin{array}{l}0 \\
0\end{array}$ & 0 \\
\hline & undrained internal friction angle & $\phi_{u} \quad$ (degree) & $\bigcirc$ & \\
\hline \multirow{2}{*}{ deformation } & $\begin{array}{l}\text { failure strain } \\
\text { remolded failure strain }\end{array}$ & $\begin{array}{ll}\varepsilon_{u} & (\mathscr{6}) \\
\varepsilon_{u r} & (\%)\end{array}$ & 0 & 0 \\
\hline & $\begin{array}{l}\text { modulus of deformation } \\
\text { remolded modulus of deformation }\end{array}$ & $\begin{array}{l}E_{50}\left(\mathrm{kgf} / \mathrm{cm}^{2}\right) \\
E_{50 r}\left(\mathrm{kgf} / \mathrm{cm}^{2}\right)\end{array}$ & $\bigcirc$ & 0 \\
\hline \multirow{2}{*}{ compressibility } & compression index & $C_{c}$ & O & \\
\hline & consolidation yield stress & $p_{c} \quad\left(\mathrm{kgf} / \mathrm{cm}^{2}\right)$ & 0 & \\
\hline soil structure & sensitivity ratio & $S_{t}$ & 0 & \\
\hline
\end{tabular}




$$
\begin{aligned}
& \text { Mechanical properties of soil } \\
& \quad=F \text { (types; states) }
\end{aligned}
$$

Where the soil types are characterized by clay mineral or chemical composition, grain size distribution and the other properties of the soil. The soil states are characterized by density, water content and soil structure, and the equation in the following form is generally obtained.

Mechanical properties of soil

$=F$ (types; density, water content, structure)

In this paper, analysis was made on the assumption that soil structure depends only on physical properties, and the validity of this assumption was examined on the basis of the analysis. Thus, the following form can be used for multiple regression analysis.

Mechanical properties of soil
$\quad=F$ (types; density, water content)

Assuming now the fully saturated state $\left(S_{r}=\right.$ 100\%) of soils, the density is dependent on water content, thus the following form is obtained.

Mechanical properties of soil $=F$ (types; density or water content)

Based on the above mentioned concepts, the regression models 1 and 2 are established as follows.

\section{Regression model 1}

The authors have made clear the relationships between shear strength and the liquidity index. The liquidity index $I_{L}$ is given by the Atterberg limits and water content $w$ as shown in Eq. (5).

$$
I_{L}=\left(w-w_{p}\right) /\left(w_{L}-w_{p}\right)
$$

where $w_{p}$ : plastic limit

$$
w_{L}: \text { liquid limit }
$$

In the liquid limit test, the relationship between the water content $w$ and the number of blows $N$ is given as shown in Eq. (6).

$$
w=-I_{f} \log N+c
$$

Where "log" is defined as a common logarithm.

$$
\begin{aligned}
& I_{f} \text { : flow index } \\
& c \text { : constant }
\end{aligned}
$$

Cohesion $c_{u}$ is assumed to be related linearly to the number of blows $N$ (Ohsaki, 1961) as shown in Eq. (7).

$$
N=k c_{u}
$$

where $k$ : constant

Substituting Eq. (7) to Eq. (6), the following Eq. (8) is obtained. If Eq. (8) is valid for the wide range of $w$ from the plastic limit $w_{p}$ to the liquid limit $w_{L}$, Eqs. (9) and (10) can be obtained.

$$
\begin{aligned}
& w=-I_{f} \log \left(k c_{u}\right)+c \\
& w_{L}=-I_{f} \log \left(k c_{u L}\right)+c \\
& w_{p}=-I_{f} \log \left(k c_{u p}\right)+c
\end{aligned}
$$

where $c_{u}$ : cohesion at natural water content $c_{u L}$ : cohesion at liquid limit $c_{u p}:$ cohesion at plastic limit

By substituting Eqs. (8), (9) and (10) to Eq. (5), the following Eq. (11) or (12) is obtained.

$$
I_{L}=\frac{\log k c_{u p}-\log k c_{u}}{\log k c_{u p}-\log k c_{u L}}=\frac{\log \left(c_{u p} / c_{u}\right)}{\log \left(c_{u p} / c_{u L}\right)}
$$

or

$$
c_{u}=c_{u p} \frac{1}{\left(c_{u p} / c_{u L}\right)^{I L}}=c_{u p}\left(c_{u p} / c_{u L}\right)^{-I_{L}}
$$

Using the relationship of $c_{u}=q_{u} / 2$, the following Eq. (13) is obtained,

$$
q_{u}=q_{u p}\left(q_{u p} / q_{u L}\right)^{-I_{L}}
$$

where $q_{u}$ is unconfined compressive strength, and rewriting the Eq. (13), the following Eq. (14) is obtained.

$$
\ln q_{u}=-\ln \left(q_{u p} / q_{u L}\right) I_{L}+\ln q_{u p}
$$

Where "ln" is defined as a natural logarithm. Now, substituting $a_{1}=-\ln \left(q_{u p} / q_{u L}\right)$ and $a_{2}=$ $\ln q_{u p}$ to Eq. (14), the following from is obtained.

$$
\ln q_{u}=a_{1} I_{L}+a_{2}
$$

Where $a_{1}$ and $a_{2}$ are determined by the multiple regression analysis using Eq. (24). In a fully saturated case, Eq. (15) is valid under the requirement of Eq. (4), but in an unsaturated case, the equation as the following form will be established to satisfy the condition shown by Eq. (3). 


$$
\ln q_{u}=b_{1} X_{1}+b_{2} I_{L}+b_{3}
$$

Where $X_{1}$ represents the variable related to the soil density, which will be described in the later examinations, and $b_{1}, b_{2}$ and $b_{3}$ are determined by the multiple regression analysis using Eq. (24).

Eq. (15) or (16) is the final form representing the regression model 1 as to the shear strength of the soil which is expressed mainly by the liquidity index.

\section{Regression model 2}

Eqs. (17) and (18) are given from the CamClay model (Roscoe, Schofield and Thurairajah, 1963).

$$
\begin{aligned}
q_{u} & =M p_{c} \\
e & =\Gamma-\lambda \ln p_{c}
\end{aligned}
$$

Where $M, \Gamma$ and $\lambda$ are constants characterized by the soil types, $p_{c}$ is the consolidation yield stress, and $e$ is the void ratio. From Eqs. (17) and (18), the following form is obtained.

$$
q_{u}=M \exp \left(\frac{\Gamma-e}{\lambda}\right)
$$

Rewriting Eq. (19), the following from,

$$
\ln q_{u}=\ln M+\Gamma / \lambda-e / \lambda
$$

is obtained. The compression index $\lambda$ is dependent on the liquid limit $w_{L}$, so that $\lambda$ can be expressed in linear form as $\lambda=a w_{L}$, referring to the linear relationship of $C_{c}=b w_{L}$ (Skempton, 1944) and also considering the relationship of $\lambda=0.434 C_{c}$. Thus Eq. (21) is obtained.

$$
\ln q_{u}=\ln M+\Gamma / a w_{L}-e / a w_{L}
$$

Substituting the following relationships to Eq. (21), Eq. (22) is obtained: $b_{1}=\Gamma / a, b_{2}=1 / a$, $b_{3} X_{2}+b_{4}=\ln M$.

$$
\ln q_{u}=b_{1} / w_{L}+b_{2} e / w_{L}+b_{3} X_{2}+b_{4}
$$

Where $X_{2}$ represents the physical property which expresses $M$, and $b_{1}, b_{2}, b_{3}$ and $b_{4}$ are determined by the multiple regression analysis using Eq. (24). Eq. (22) is the finally established form as the regression model 2 based on the Cam-Clay model. However, it must be remarked that Eq. (22) is valid only for fully saturated soil.

Independent variables $X_{1}$ and $X_{2}$ in Eqs.
(16) and (22) will be determined respectively by examining the magnitude of the contribution of independent variables to a dependent variable during the course of the analysis. The magnitude of the contribution can be shown by $F$-values during analysis. The regression models 1 and 2 could be adopted for mechanical properties other than shear strength as will be shown later in this paper, because shear strength is usually related lineally to the other mechanical properties (JSSMFE, 1966; Hirata, 1985).

\section{Method of Analysis}

Regression models are based on linear regression as shown in Eq. (23). Transforming the dependent variables into logarithmic form, Eq. (24) will be adopted to non-linear regression (loglinear regression).

$$
\begin{aligned}
y=a_{1} x_{1}+a_{2} x_{2}+\cdots \cdots+a_{m} x_{m}+a_{m+1} \\
Y=\ln y=b_{1} x_{2}+b_{2} x_{2}+ \\
\cdots \cdots+b_{m} x_{m}+b_{m+1}
\end{aligned}
$$

Where $y$ is the dependent variable(mechanical property), $x_{i}$ is the independent variable (physical property), $m$ is the number of independent variables, $Y$ is the dependent variable transformed to the logarithm.

Multiple correlation coefficient, partial correlation coefficient and $F$-value are used to examine the process and result of multiple regression analysis, and are defined as follows (Kobayashi, 1982; Flury and Riedwyl, 1988).

\section{Multiple correlation coefficient}

The multiple correlation coefficient $R$ expresses the magnitude of predictive accuracy of the regression equation as shown in Eq. (25).

$$
\left.\begin{array}{l}
R=S_{y_{0} y} / \sqrt{S_{y_{0} y_{0}} \cdot S_{y y}} \\
S_{y_{0} y_{0}}=\sum_{i=1}^{n}\left(y_{0 i}-\bar{y}_{0}\right)^{2} \\
S_{y y}=\sum_{i=1}^{n}\left(y_{i}-\bar{y}\right)^{2} \\
S_{y_{0} y}=\sum_{i=1}^{n}\left(y_{0 i}-\bar{y}_{0}\right)\left(y_{i}-\bar{y}\right)
\end{array}\right\}
$$

where

$S_{y_{0} y_{0}}$ : sum of square of measured values $y_{0}$

$S_{y y}$ : sum of square of predicted values $y$

$S_{y_{0} y}$ : partial sum of square of $y_{0}$ and $y$ 
$\bar{y}_{0}:$ average value of $y_{0}$

$\bar{y}$ : average value of $y$

$n$ : number of data samples

\section{Partial correlation coefficient}

The partial correlation coefficient $r$ expresses the magnitude of the relationship among the variables excluding the influence of the other variables. In this paper, the partial correlation coefficient was mainly used to estimate how strongly physical properties contribute to a mechanical property excluding the influence of the other physical properties.

The partial correlation coefficient could be more practically explained by using the following example of regression equation.

$$
y=a_{1} x_{1}+a_{2} x_{2}+a_{3} x_{3}+a_{4}
$$

When the relationship between $y$ and $x_{1}$ excluding the influence of $x_{2}$ and $x_{3}$ is taken into account, as the first step, regression analysis for the following form is employed,

$$
y=b_{2} x_{2}+b_{3} x_{3}+b_{4}
$$

and as the result of the analysis, $\hat{b}_{2}, \hat{b}_{3}, \hat{b}_{4}$ are obtained as predicted values of $b_{2}, b_{3}, b_{4}$. Then $y^{\prime}$ is calculated as follows.

$$
y^{\prime}=y-\left(\hat{b}_{2} x_{2}+\hat{b}_{3} x_{3}+\hat{b}_{4}\right)
$$

As the second step, the regression analysis with the following form is employed,

$$
x_{1}=c_{2} x_{2}+c_{3} x_{3}+c_{4}
$$

and as the result of the analysis, $\hat{c}_{2}, \hat{c}_{3}, \hat{c}_{4}$ are obtained as predicted values of $c_{2}, c_{3}, c_{4}$. Then $x_{1}{ }^{\prime}$ is calculated as follows.

$$
x_{1}^{\prime}=x_{1}-\left(\hat{c}_{2} x_{2}+\hat{c}_{3} x_{3}+\hat{c}_{4}\right)
$$

Finally, the partial correlation coefficient is obtained by calculating the multiple correlation coefficient $R$ of Eq. (25) between $y^{\prime}$ and $x_{1}{ }^{\prime}$, and is expressed by the symbol $r_{y x_{1} \cdot x_{2} x_{3}}$ as follows.

$$
r_{y x_{1} \cdot x_{2} x_{3}}=S_{y^{\prime} x_{1}^{\prime}} / \sqrt{S_{y^{\prime} y^{\prime}} \cdot S_{x_{1}^{\prime} x_{1}^{\prime}}}
$$

\section{F-value}

$F$-value is expressed as follows in the case of the example used above.

$$
F_{y x_{1} \cdot x_{2} x_{3}}=r_{y x_{1} \cdot x_{2} x_{3}}{ }^{2}(n-k) /\left(1-r_{y x_{1} \cdot x_{2} x_{3}}{ }^{2}\right)
$$

where

$r_{y x_{1} \cdot x_{2} x_{3}}$ : partial correlation coefficient between the dependent variable $y$ and the independent variable $x_{1}$.

$n-k$ : degree of freedom, $n$ is the number of data samples, and $k$ is the number of independent variables plus one.

$F$-value is the alternative expression of partial correlation coefficient $r$ shown by Eq. (26). During the regression analysis, $F$-values are effectively used to select the important independent variables which contribute significantly to dependent variables. Those independent variables are selected in step by step analytical procedure as explained in later chapter ; RESULTS OF MULTIPLE REGRESSION ANALYSIS.

\section{DATA USED IN THE ANALYSIS}

The data samples of both natural and artificially mixed soils with a clay content of more than 20\% were used in multiple regression analysis. The outlines of these data are as follows.

\section{Data of Natural Soils}

The data of natural soils was collected from site investigation results in Osaka and Hyogo (Yao, Hirata and Saito, 1985a). The grain size distributions of soil samples are given in Fig. 1, and the total number of data samples is 734. The method of the physical property tests and that of the mechanical property tests conformed to the JSSMFE standard.

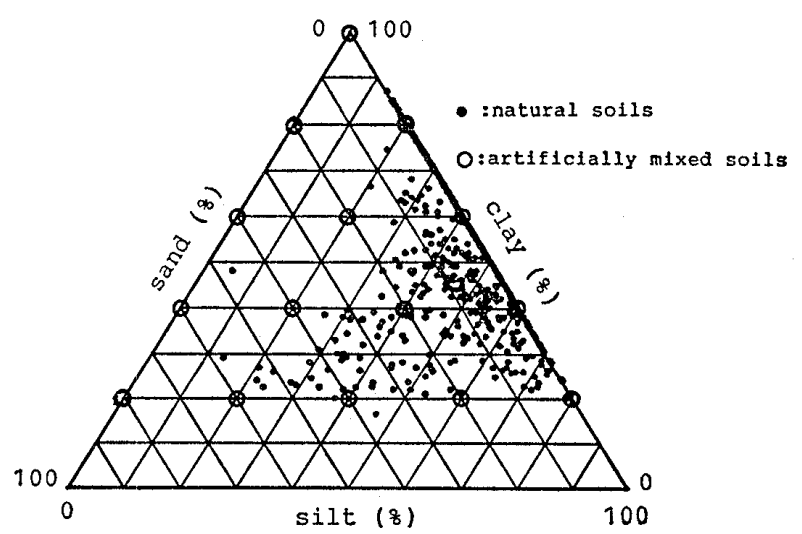

Fig. 1. Grain size distribution of natural and artificially mixed soils 
The unconfined compression test was carried out with a constant rate of axial strain of $1 \% / \mathrm{min}$. The average value of the degree of saturation in the sample was $99.46 \%$ and the value of standard deviation was $2.00 \%$.

In the JSSMFE (1979) it is remarked that liquidity index is underestimated as compared with that of the original soil, because the Atterberg limit tests were performed on soil fraction smaller than $420 \mu \mathrm{m}$, while the water content test was performed on the soil sample of original grain size To compensate for this underestimate, the correcting coefficient $T$ given by Eq. (28) is introduced here, based on the fact that a grain size of $420 \mu \mathrm{m}$ is approximately in the middle between the upper and lower bounds of sand grain size on the logarithmic scale. Eq. (28) means that half of the sand contest $S$ of the soils used in the Atterberg limit tests are removed from the original soils. Thus the plastic limit and liquid limit should be corrected respectively by Eqs. (29) and (30). The plasticity index $I_{p}$ and liquidity index $I_{L}$ are obtained using the values of Eqs. (29) and (30).

$$
\begin{aligned}
& T=\left(C+M_{o}+S / 2\right) / 100 \\
& w_{p}=T w_{p t} \\
& w_{L}=T w_{L t}
\end{aligned}
$$

where $T$ : correcting coefficient

$C$ : clay content (\%)

$M_{0}:$ silt content $(\%)$

$S$ : sand content (\%)

$w_{p}$ : corrected plastic limit $(\%)$

$w_{p t}:$ measured plastic limit $(\%)$

$w_{L}:$ corrected liquid limit (\%)

$w_{L t}:$ measured liquid limit $(\%)$
Data of Artificially Mixed Soils

Artificially mixed soils are composed of clay (either bentonite or kaolinite), silt (rubble dust) and sand (Toyoura sand) as shown in Fig. 1 (Yao, Hirata and Saito, 1985b). The grain size distribution curves are shown in Fig. 2, and the physical properties are given in Table 3. Artificially mixed soils in Fig. 1 were thoroughly remolded at a water content of the liquidity index $I_{L}=0$ (i.e., $w=w_{p}$ ), and were compacted into a mold of $50 \mathrm{~mm}$ in diameter and $100 \mathrm{~mm}$ in height. Soils with a sand content of $0 \%$ and at a water cotent with liquidity indexes of $I_{L}=0.25,0.50$ and 0.75 were used to make the test specimens to examine the influence of the magnitude of water contents. The physical property tests conformed also to the JSSMFE standard. The unconfined compression test was performed with a constant rate of axial strain of $5 \% / \mathrm{min}$. The total number of data samples was 120 . The average value of the degree of saturation was $90.69 \%$ and the value of standard deviation was $5.02 \%$.

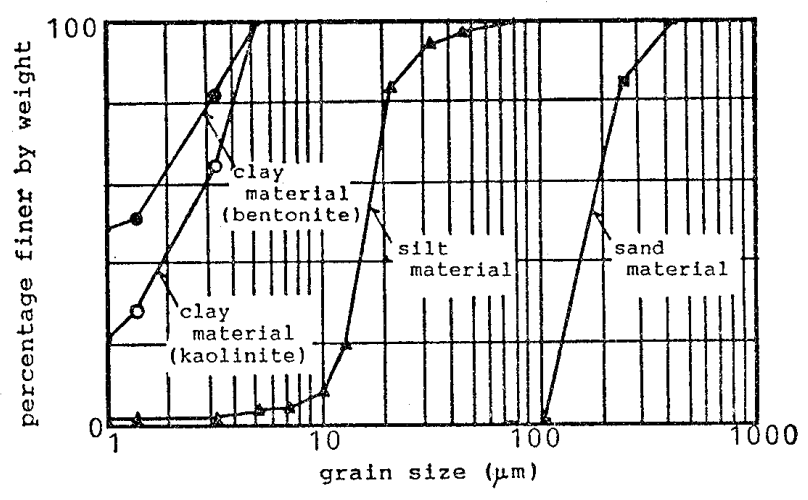

Fig. 2. Grain size distribution curves of mixed

\begin{tabular}{|c|c|c|c|c|c|c|c|c|c|}
\hline material & $\underset{(\mu \mathrm{m})}{D \max }$ & $\begin{array}{c}D_{10} \\
(\mu \mathrm{m})\end{array}$ & $U_{c}$ & $U_{c^{\prime}}$ & $\begin{array}{l}w_{L} \\
(\not 6)\end{array}$ & $\begin{array}{c}w_{p} \\
(\%)\end{array}$ & $\begin{array}{l}I_{p} \\
(\mathscr{\varphi})\end{array}$ & $P_{r}$ & $A=$ \\
\hline clay (kaolinite) & 5 & - & - & - & 49.5 & 32.1 & 17.3 & 0.5 & 0.43 \\
\hline clay (bentonite) & 5 & - & - & 一 & 158.8 & 47.2 & 111.6 & 2.4 & 1.82 \\
\hline ... & 74 & 10.3 & 1.8 & 1.10 & 39.5 & 26.5 & 12.9 & 0.5 & 4.78 \\
\hline sand & 420 & 121.1 & 1.7 & 0.96 & - & - & - & - & - \\
\hline
\end{tabular}
materials

Table 3. Physical properties of mixed materials 


\section{RESULTS OF MULTIPLE REGRESSION ANALYSIS}

The regression equations obtained by multiple regression analysis are given in Table 4 for natural soils, and in Table 14 for artificially mixed soils. In these tables, the total number of data samples $n$, the multiple correlation coefficient $R$ and the regression equation numbers (REN is used for natural soils and
REA is used for artificially mixed soils) are given together with the regression equation. The partial correlation coefficients $r$ are also given respectively below each partial regression coefficient.

In order to show the regression procedure, $F$-values that express shifts in the magnitude of contribution to the dependent variable during analysis, are given respectively for some trpical results in Table 5 to 13 for natural

Table 4. Results of multiple regression analysis for natural soils

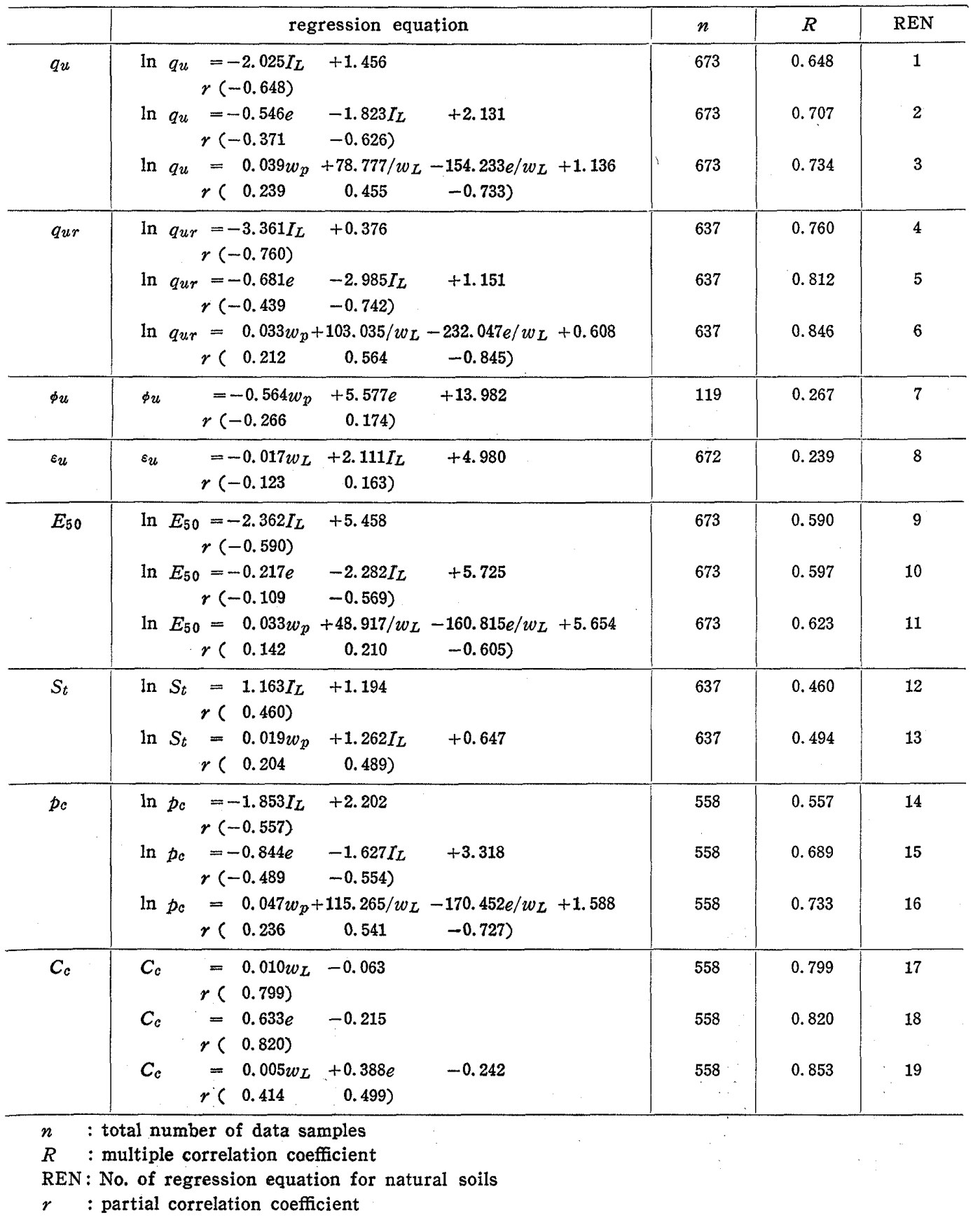


Table 5. $F$-values for $\ln q_{u}\left(e, I_{L}\right)$ : REN 2

\begin{tabular}{l|r|r|r}
\hline & Initiation & \multicolumn{1}{|c|}{ 1 st step } & \multicolumn{1}{c}{2 nd step } \\
\hline$C$ & 3.3006 & 66.3336 & 1.7891 \\
$M_{0}$ & 5.0461 & 8.4816 & 0.8043 \\
$S$ & 0.0299 & 66.6607 & 6.9641 \\
$1 / w_{L}$ & 0.3157 & 73.7648 & 1.5888 \\
$w_{L}$ & 0.1796 & 41.7440 & 56.3577 \\
$w_{p}$ & 2.7009 & 10.6578 & 64.6694 \\
$I_{p}$ & 0.0179 & 55.1328 & 16.8982 \\
$P_{r}$ & 0.6147 & 84.6820 & 5.5513 \\
$r_{t}$ & 133.3190 & 86.6571 & 0.5280 \\
$e / w_{L}$ & 453.2770 & 6.0972 & 30.1400 \\
$e$ & 143.8190 & 107.1370 & $* 104.1370$ \\
$w$ & 132.5280 & 97.4184 & 5.1358 \\
$S_{r}$ & 4.1715 & 3.6347 & 0.2747 \\
$I_{L}$ & 484.8230 & $* 484.8230$ & $* 432.3700$ \\
\hline
\end{tabular}

Table 6. $F$-values for $\ln q_{u}\left(w_{p}, 1 / w_{L}, \mathbf{e} / w_{L}\right)$ : REN 3

\begin{tabular}{l|r|r|r|r}
\hline & Initiation & \multicolumn{1}{|c|}{ 1 st step } & 2 nd step & 3 rd step \\
\hline$C$ & 3.3006 & 103.0550 & 8.6930 & 10.4832 \\
$M_{0}$ & 5.0461 & 17.4400 & 2.8402 & 2.8123 \\
$S$ & 0.0299 & 81.7994 & 0.3038 & 0.7093 \\
$1 w_{L}$ & 0.3157 & 147.9770 & $* 147.9770$ & $* 174.2430$ \\
$w_{L}$ & 0.1796 & 110.8220 & 0.9884 & 24.0475 \\
$w_{p}$ & 2.7009 & 18.3536 & 40.6151 & $* 40.6151$ \\
$I_{p}$ & 0.0179 & 132.9660 & 9.1386 & 27.5854 \\
$P_{r}$ & 0.6147 & 193.2120 & 52.4098 & 24.2547 \\
$\gamma t$ & 133.3190 & 138.5170 & 2.8615 & 22.0752 \\
$e / w_{L}$ & 453.2770 & $* 453.2770$ & $* 699.8960$ & $* 774.5030$ \\
$e$ & 143.8190 & 161.3590 & 13.4881 & 46.6955 \\
$w$ & 132.5280 & 161.9580 & 15.1544 & 59.5024 \\
$S_{r}$ & 4.1715 & 18.3063 & 1.4378 & 1.0552 \\
$I_{L}$ & 484.8230 & 25.0677 & 4.3214 & 1.2959 \\
\hline
\end{tabular}

Table 7. $F$-values for $\ln q_{u r}\left(e, I_{L}\right)$ : REN 5

\begin{tabular}{l|r|r|r}
\hline & Initiation & \multicolumn{1}{|c|}{ 1 st step } & \multicolumn{1}{c}{ 2 nd step } \\
\hline$C$ & 3.7128 & 57.4071 & 0.8312 \\
$M_{0}$ & 0.7927 & 0.2189 & 31.9237 \\
$S$ & 4.6769 & 156.3160 & 41.2348 \\
$1 / w_{L}$ & 3.4679 & 148.7420 & 7.2141 \\
$w_{L}$ & 0.1881 & 59.5438 & 93.5772 \\
$w_{p}$ & 0.3435 & 58.5555 & 10.8731 \\
$I_{p}$ & 0.1166 & 66.4413 & 49.0977 \\
$P_{r}$ & 0.7150 & 70.8508 & 0.2784 \\
$r_{t}$ & 211.7700 & 148.7310 & 4.2843 \\
$e / w_{L}$ & 720.4270 & 6.6029 & 48.8392 \\
$e$ & 201.3270 & 150.9400 & $* 150.9400$ \\
$w$ & 186.7240 & 136.8020 & 6.0014 \\
$S_{r}$ & 16.9245 & 13.6716 & 1.1886 \\
$l_{L}$ & 869.5470 & $* 869.5470$ & $* 778.1030$ \\
\hline
\end{tabular}

Table 8. $\boldsymbol{F}$-values for $\ln \boldsymbol{q}_{u r}\left(\boldsymbol{w}_{p}, \mathbf{1} / \boldsymbol{w}_{L}, \mathrm{e} / \boldsymbol{w}_{L}\right)$ : REN 6

\begin{tabular}{l|r|r|r|r}
\hline & Initiation & \multicolumn{1}{c|}{ 1 st step } & 2 nd step & 3 rd step \\
\hline$C$ & 3.7128 & 112.0430 & 0.9645 & 0.5610 \\
$M_{0}$ & 0.7927 & 2.8793 & 7.1758 & 6.9675 \\
$S$ & 4.6769 & 196.0700 & 2.7054 & 3.2069 \\
$1 / w_{L}$ & 3.4679 & 366.2650 & $* 366.2650$ & $* 295.4870$ \\
$w_{L}$ & 0.1881 & 196.1030 & 3.2650 & 1.0279 \\
$w_{p}$ & 0.3435 & 79.8744 & 29.6475 & $* 29.6475$ \\
$I_{p}$ & 0.1166 & 204.5790 & 0.1055 & 1.7392 \\
$P_{r}$ & 0.7150 & 231.9440 & 14.7861 & 2.4666 \\
$\tau_{t}$ & 211.7700 & 287.6680 & 0.0701 & 7.2836 \\
$e / w_{L}$ & 720.4270 & $* 720.4270$ & $* 1489.5000$ & $* 1580.7600$ \\
$e$ & 201.3270 & 280.8150 & 0.0043 & 6.1218 \\
$w$ & 186.7240 & 290.0570 & 1.6809 & 18.3904 \\
$S_{r}$ & 16.9245 & 55.1166 & 11.6323 & 10.6697 \\
$I_{L}$ & 869.5470 & 77.0799 & 14.8507 & 6.8224 \\
\hline
\end{tabular}

Table 9. $F$-values for $\ln E_{50}\left(e, I_{L}\right)$ : REN 10

\begin{tabular}{l|r|r|r}
\hline & \multicolumn{1}{|c|}{ Initiation } & \multicolumn{1}{|c}{ 1 st step } & \multicolumn{1}{c}{ 2nd step } \\
\hline$C$ & 1.3764 & 9.6503 & 2.3777 \\
$M_{0}$ & 0.3641 & 0.5064 & 0.1533 \\
$S$ & 5.5121 & 11.9633 & 4.7688 \\
$1 / w_{L}$ & 22.8023 & 2.0151 & 6.7374 \\
$w_{L}$ & 17.3540 & 0.3116 & 29.0940 \\
$w_{p}$ & 17.3211 & 0.3025 & 21.4382 \\
$I_{p}$ & 15.4126 & 1.5212 & 10.1060 \\
$P_{r}$ & 10.9505 & 4.9760 & 0.0265 \\
$r t$ & 30.6444 & 4.7893 & 1.6608 \\
$e / w_{L}$ & 376.4110 & 17.6356 & 26.2034 \\
$e$ & 33.1410 & 7.9924 & $* 7.9924$ \\
$w$ & 32.5544 & 8.1715 & 0.1771 \\
$S_{r}$ & 2.4610 & 1.6338 & 0.3655 \\
$I_{L}$ & 358.3140 & $* 358.3140$ & $* 321.0900$ \\
\hline
\end{tabular}

Table 10. $F$-values for $\ln E_{50}\left(w_{p}, 1 / w_{L}, e / w_{L}\right)$ : REN 11

\begin{tabular}{l|r|r|r|r}
\hline & Initiation & \multicolumn{1}{|c}{ 1 st step } & 2nd step & 3rd step \\
\hline$C$ & 1.3764 & 24.1081 & 8.0684 & 8.9132 \\
$M_{0}$ & 0.3641 & 3.5136 & 0.8605 & 0.8155 \\
$S$ & 5.5121 & 20.2011 & 4.4611 & 5.2686 \\
$1 / w_{L}$ & 22.8023 & 17.0755 & $* 17.0755$ & $* 30.8518$ \\
$w_{L}$ & 17.3540 & 14.2113 & 0.3081 & 7.7134 \\
$w_{p}$ & 17.3211 & 0.2615 & 13.7252 & $* 13.7252$ \\
$I_{p}$ & 15.4126 & 19.4558 & 3.2252 & 9.1524 \\
$P_{r}$ & 10.9505 & 31.6207 & 14.2472 & 5.6385 \\
$r t$ & 30.6444 & 16.6648 & 0.5336 & 5.7635 \\
$e / w_{L}$ & 376.4110 & $* 376.4110$ & $* 367.2560$ & $* 386.7120$ \\
$e$ & 33.1410 & 21.1733 & 4.0182 & 13.7471 \\
$w$ & 32.5544 & 25.2540 & 8.6256 & 26.0565 \\
$S_{r}$ & 2.4610 & 11.7666 & 5.5567 & 5.1043 \\
$l_{L}$ & 358.3140 & 5.7546 & 1.6989 & 0.5428 \\
\hline
\end{tabular}


Table 11. $F$-values for $\ln p_{c}\left(e, I_{L}\right): \operatorname{REN} 15$

\begin{tabular}{l|r|r|r}
\hline & \multicolumn{1}{|c|}{ Initiation } & \multicolumn{1}{|c}{ 1 st step } & \multicolumn{1}{|c}{ 2 nd step } \\
\hline$C$ & 14.2256 & 110.4360 & 5.7362 \\
$M_{0}$ & 6.4432 & 15.2609 & 1.1086 \\
$S$ & 9.1299 & 127.8880 & 24.3782 \\
$1 / w_{L}$ & 5.2462 & 152.9410 & 1.6706 \\
$w_{L}$ & 3.2416 & 73.0560 & 70.9743 \\
$w_{p}$ & 0.1343 & 27.6216 & 75.8936 \\
$I_{p}$ & 4.1086 & 85.1616 & 32.8047 \\
$P_{r}$ & 9.1404 & 122.9810 & 3.0803 \\
$\gamma_{t}$ & 160.3740 & 149.0060 & 0.1102 \\
$e / w_{L}$ & 227.0170 & 0.2004 & 30.7790 \\
$e$ & 177.9340 & 174.4650 & $* 174.4650$ \\
$w$ & 169.2680 & 165.8630 & 1.7534 \\
$S_{r}$ & 14.5566 & 12.5769 & 0.2300 \\
$I_{L}$ & 249.6210 & $* 249.6210$ & $* 245.7150$ \\
\hline
\end{tabular}

Table 12. $F$-values for $\ln p_{c}\left(w_{p}, 1 / w_{L}, e / w_{L}\right):$ REN 16

\begin{tabular}{l|r|r|r|r}
\hline & Initiation & \multicolumn{1}{|c|}{1 st step } & 2 nd step & 3 rd step \\
\hline$C$ & 14.2256 & 144.5940 & 9.9852 & 9.5321 \\
$M_{0}$ & 6.4432 & 23.2416 & 1.8018 & 1.2004 \\
$S$ & 9.1299 & 135.8150 & 2.8803 & 3.4054 \\
$1 / w_{L}$ & 5.2462 & 249.1410 & $* 249.1410$ & $* 228.6540$ \\
$w_{L}$ & 3.2416 & 141.6810 & 0.1862 & 14.7117 \\
$w_{p}$ & 0.1343 & 47.7759 & 32.6690 & $* 32.6690$ \\
$I_{p}$ & 4.1086 & 155.9280 & 1.1297 & 14.3845 \\
$P_{r}$ & 9.1404 & 208.0920 & 24.9356 & 9.7018 \\
$r t$ & 160.3740 & 202.0170 & 0.6151 & 15.2933 \\
$e / w_{L}$ & 227.0170 & $* 227.0170$ & $* 566.8900$ & $* 620.7970$ \\
$e$ & 177.9340 & 235.5660 & 6.7244 & 37.7199 \\
$w$ & 169.2680 & 232.7480 & 8.0094 & 51.4208 \\
$S_{r}$ & 14.5566 & 28.1633 & 2.0851 & 1.4482 \\
$I_{L}$ & 249.6210 & 16.2274 & 0.3237 & 0.0070 \\
\hline
\end{tabular}

soils and in Table 15 to 18 for artificially mixed soils. In the column of Initiation of these tables, $F$-values for all independent variables are given. In the column of the $1 \mathrm{st}$ step, $F$-values for all independent variables excluding one independent variable marked by * that is included in the regression equation already are given. In the column of the 2 nd step, $F-$ values for all independent variables excluding two independent variables marked by $*$ that are succeedingly included in the regression equation already are shown. In the column of the $3 \mathrm{rd}$ step, final $F$-values obtained by similar procedures are given.

In Fig. 3 to 8 , the relationships between

Table 13. $F$-values for $C_{c}\left(e, w_{L}\right):$ REN 19

\begin{tabular}{l|r|r|r}
\hline & Initiation & 1 st step & \multicolumn{1}{|c}{ 2nd step } \\
\hline$C$ & 242.8720 & 6.1236 & 2.5250 \\
$M_{0}$ & 79.3593 & 1.9933 & 0.0771 \\
$S$ & 118.9110 & 1.6926 & 3.1572 \\
$1 / w_{L}$ & - & - & - \\
$w_{L}$ & 979.4710 & 114.5670 & $* 114.5670$ \\
$w_{p}$ & 605.1300 & 69.5421 & 2.7529 \\
$I_{p}$ & 879.1560 & 100.2890 & 1.6210 \\
$P_{r}$ & 403.3830 & 34.1377 & 1.7919 \\
$r t$ & 814.1970 & 0.4260 & 0.1211 \\
$e / w_{L}$ & - & - & - \\
$e$ & 1138.4700 & $* 1138.4700$ & $* 183.8990$ \\
$w$ & 1103.2700 & 0.2647 & 7.9267 \\
$S_{r}$ & 21.2529 & 2.1582 & 2.6365 \\
$I L$ & 2.3547 & 79.4070 & 0.8828 \\
\hline
\end{tabular}

Table 14. Results of multiple regression analysis for artificially mixed soils

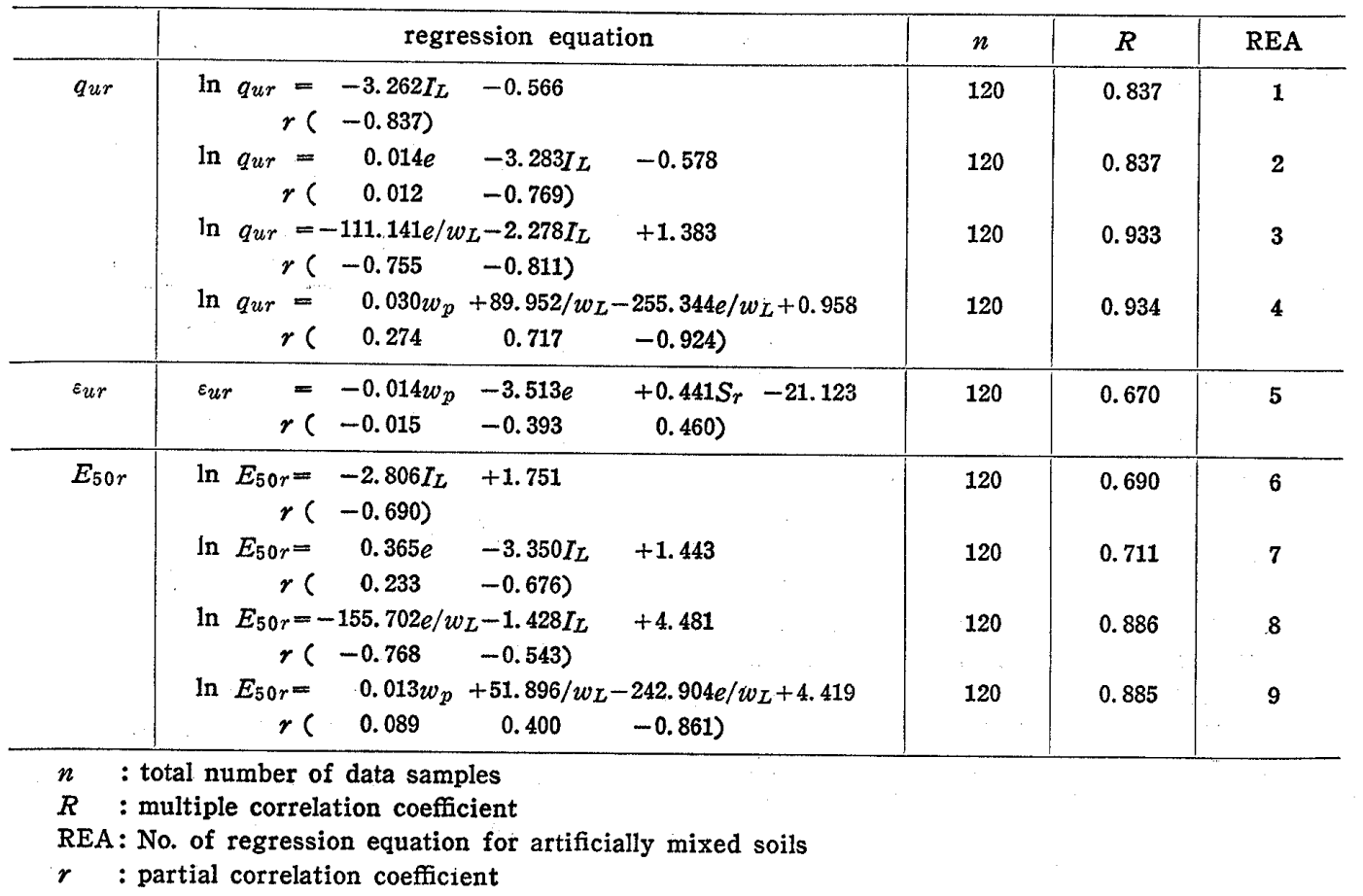


Table 15. $F$-values for $\ln q_{u r}\left(e / w_{L}, I_{L}\right)$ : REA3

\begin{tabular}{l|r|r|r}
\hline & \multicolumn{1}{|c|}{ Initiation } & \multicolumn{1}{|c|}{ 1 st step } & \multicolumn{1}{c}{ 2nd step } \\
\hline$C$ & 0.0806 & 9.1389 & 6.1256 \\
$M_{0}$ & 10.3883 & 1.1461 & 2.0333 \\
$S$ & 20.6713 & 8.6415 & 2.4486 \\
$1 / w_{L}$ & 0.3908 & 59.2115 & 11.2489 \\
$w_{L}$ & 0.2216 & 16.8603 & 11.4434 \\
$w_{p}$ & 9.1430 & 6.4209 & 2.9428 \\
$I_{p}$ & 0.0086 & 18.2226 & 13.2176 \\
$P_{r}$ & 2.1004 & 31.7494 & 18.2803 \\
$\gamma_{t}$ & 46.6368 & 0.9956 & 14.1844 \\
$e / w_{L}$ & 194.2390 & 154.9370 & $* 154.9370$ \\
$e$ & 42.5928 & 0.0173 & 7.9464 \\
$w$ & 44.8130 & 0.0295 & 8.5808 \\
$S_{r}$ & 6.0383 & 2.1235 & 0.8651 \\
$I_{L}$ & 274.9380 & $* 274.9380$ & $* 225.2200$ \\
\hline
\end{tabular}

Table 16. $F$-values for $\ln q_{u r}\left(w_{p}, 1 / w_{L}, e / w_{L}\right)$ : REA 4

\begin{tabular}{l|r|r|r|r}
\hline & Initiation & 1 st step & 2 nd step & 3 rd step \\
\hline$C$ & 0.0806 & 0.8090 & 51.5708 & 39.6135 \\
$M_{0}$ & 10.3883 & 8.6895 & 12.7345 & 6.4424 \\
$S$ & 20.6713 & 26.7087 & 13.2824 & 9.7432 \\
$1 / w_{L}$ & 0.3908 & 202.3090 & $* 202.3090$ & $* 122.4820$ \\
$w_{L}$ & 0.2216 & 81.4053 & 0.2063 & 4.5889 \\
$w_{p}$ & 9.1430 & 50.9650 & 9.4477 & $* 9.4477$ \\
$I_{p}$ & 0.0086 & 81.6924 & 0.0384 & 4.6168 \\
$P_{r}$ & 2.1004 & 115.4490 & 4.7682 & 4.4824 \\
$\gamma_{t}$ & 46.6368 & 130.3080 & 0.4423 & 0.4902 \\
$e / w_{L}$ & 194.2390 & $* 194.2390$ & $* 725.1320$ & $* 680.4130$ \\
$e$ & 42.5928 & 76.5303 & 2.4692 & 0.0945 \\
$w$ & 44.8130 & 82.6755 & 1.6650 & 0.0192 \\
$S_{r}$ & 6.0383 & 20.2508 & 2.8707 & 6.3503 \\
$I_{L}$ & 274.9380 & 225.2200 & 20.3792 & 11.7779 \\
\hline
\end{tabular}

Table 17. $F$-values for $\ln E_{50 r}\left(e / w_{L}, I_{L}\right)$ : REA8

\begin{tabular}{l|r|r|r}
\hline & Initiation & \multicolumn{1}{|c}{ 1 st step } & \multicolumn{1}{c}{ 2 nd step } \\
\hline$C$ & 0.2653 & 8.8739 & 5.9113 \\
$M_{0}$ & 13.8576 & 4.3945 & 9.6809 \\
$S$ & 15.8512 & 1.7046 & 0.8630 \\
$1 / w_{L}$ & 2.2936 & 82.8847 & 1.9186 \\
$w_{L}$ & 4.3947 & 49.5806 & 0.6198 \\
$w_{p}$ & 2.3286 & 9.1993 & 1.1421 \\
$I_{p}$ & 8.1918 & 59.5417 & 1.4803 \\
$P_{r}$ & 22.5211 & 109.4920 & 5.0998 \\
$r_{t}$ & 11.3193 & 14.0776 & 0.3196 \\
$e / w_{L}$ & 269.6670 & 168.5570 & $* 168.5570$ \\
$e$ & 11.4491 & 6.7008 & 0.9407 \\
$w$ & 13.1793 & 5.8058 & 0.2947 \\
$S_{r}$ & 16.1111 & 3.0309 & 54.4823 \\
$I_{L}$ & 107.3850 & $* 107.3850$ & $* 49.0191$ \\
\hline
\end{tabular}

Table 18. $F$-values for $\ln E_{50 r}\left(w_{p}, 1 / w_{L}, e / w_{L}\right)$ : REA 9

\begin{tabular}{l|r|r|r|r}
\hline & Initiation & 1 st step & 2 nd step & 3 rd step \\
\hline$C$ & 0.2653 & 0.1723 & 20.5355 & 24.2848 \\
$M_{0}$ & 13.8576 & 16.6270 & 17.2389 & 16.6727 \\
$S$ & 15.8512 & 21.0162 & 0.0594 & 0.2076 \\
$1 / w_{L}$ & 2.2936 & 45.3908 & $* 45.3908$ & $* 22.0799$ \\
$w_{L}$ & 4.3947 & 10.6601 & 11.7242 & 13.8704 \\
$w_{p}$ & 2.3286 & 20.5085 & 0.9227 & $* 0.9227$ \\
$I_{p}$ & 8.1918 & 8.1440 & 13.6689 & 13.8141 \\
$P_{r}$ & 22.5211 & 6.9862 & 16.4512 & 16.9400 \\
$\gamma_{t}$ & 11.3193 & 18.3636 & 21.0774 & 21.0877 \\
$e / w_{L}$ & 269.6670 & $* 269.6670$ & $* 406.3330$ & $* 333.4860$ \\
$e$ & 11.4491 & 10.4463 & 17.3369 & 17.0172 \\
$w$ & 13.1793 & 13.4123 & 11.3828 & 10.7818 \\
$S_{r}$ & 16.1111 & 89.3236 & 60.3837 & 72.3494 \\
$I_{L}$ & 107.3850 & 49.0191 & 4.5533 & 3.5710 \\
\hline
\end{tabular}

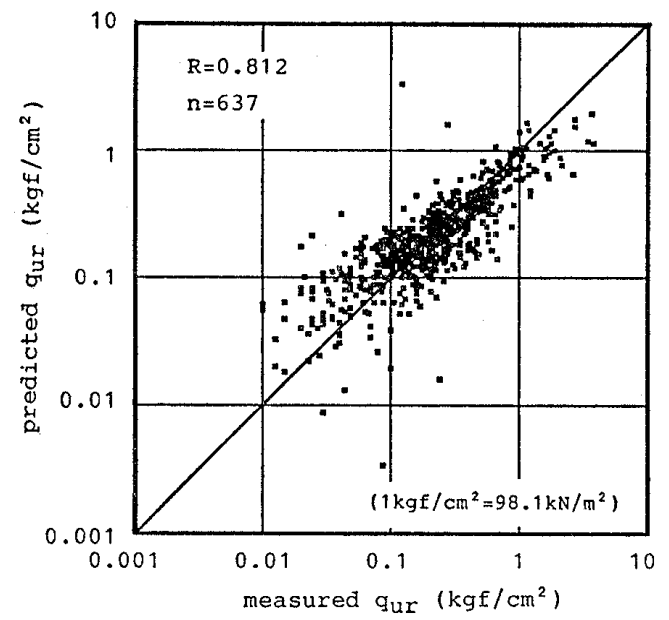

Fig. 3. Relationship between measured and predicted $\boldsymbol{q}_{u r}:$ REN5

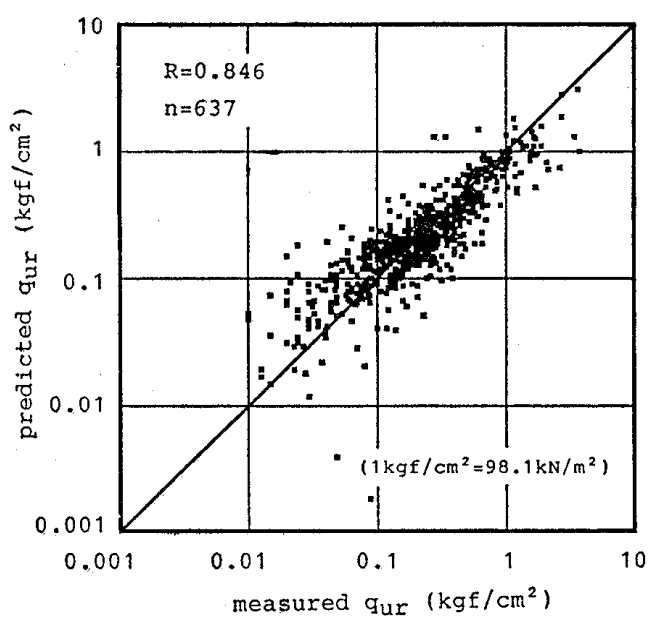

Fig. 4. Relationship between measured and predicted $q_{u r}:$ REN6 


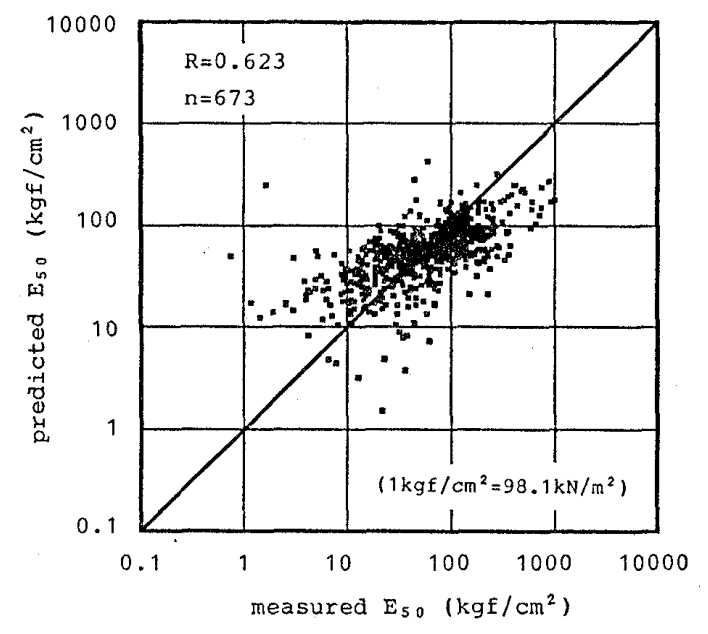

Fig. 5. Relationship between measured and predicted $\mathbf{E}_{50}:$ REN11

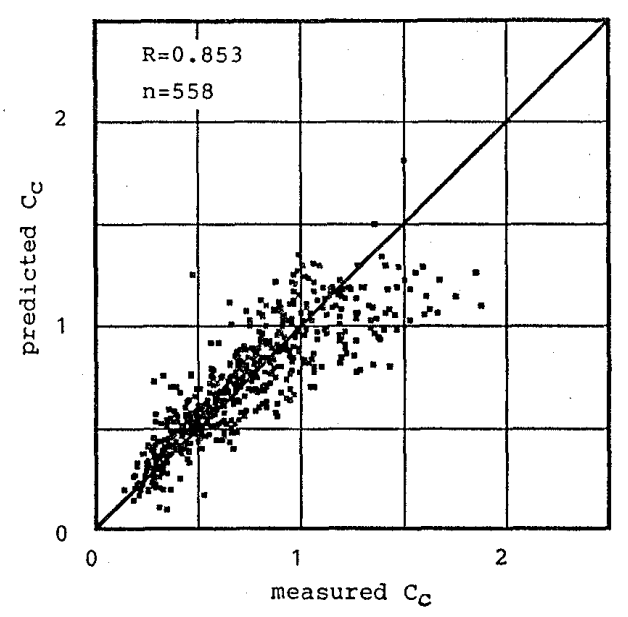

Fig. 6. Relationship between measured and predicted $C_{c}:$ REN19

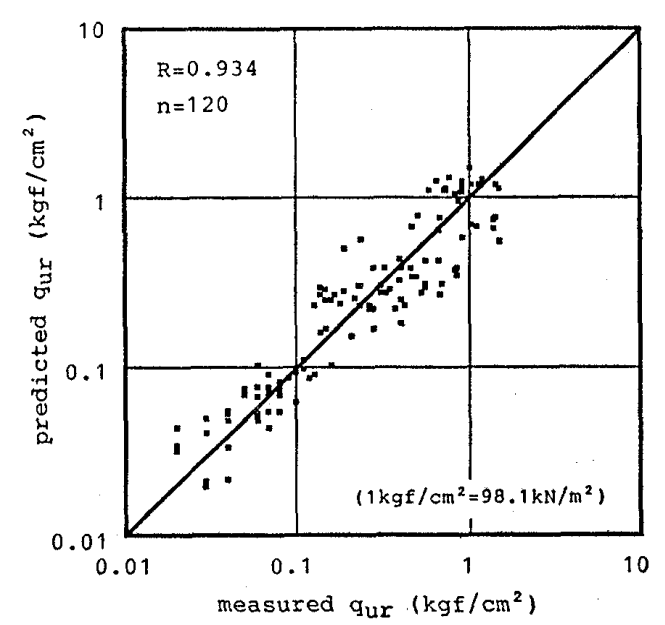

Fig. 7. Relationship between measured and predicted $q_{u r}:$ REA4

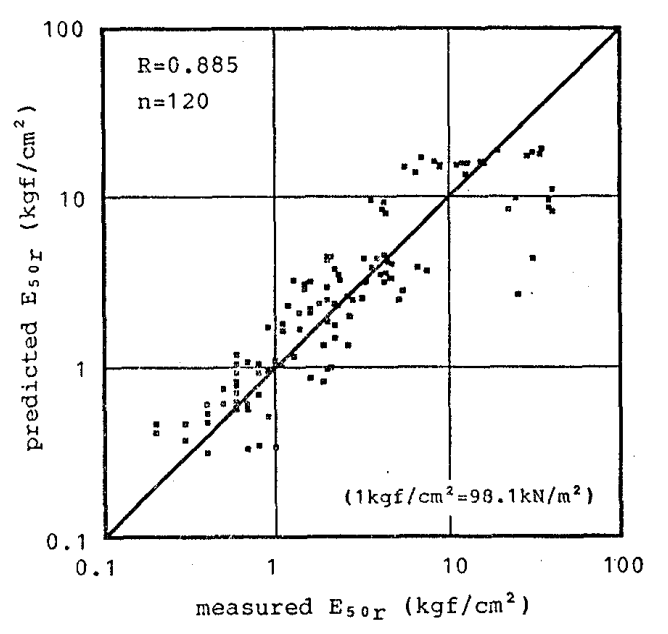

Fig. 8. Relationship between measured and predicted $\mathbf{E}_{50 r}$ : REA9

the measured and predicted values are given respectively for some typical results.

\section{DISCUSSION}

Comparisons with Single Regression Analysis in the Past

On unconfined compressive strength

Fig. 9 shows the relationships between the remolded unconfined compressive strength $q_{u r}$ and the liquidity index $I_{L}$, which were obtained by Mikasa (1967) and by the authors. Mikasa's curve was obtained as the standard curve of the remolded cohesive soil by using the relationship of $q_{u r}=2 c_{u r}$. This standard curve had been determined by three points which are given by experimental values of cohesion at the remolded state $c_{u r}$ of $0.1,1.0$ and $10 \mathrm{tf} / \mathrm{m}^{2}\left(0.981,9.81\right.$ and $\left.98.1 \mathrm{kN} / \mathrm{m}^{2}\right)$ correspond to liquidity index $I_{L}$ of $1.0,0.4$ and 0.1 , respectively. The curve of REN4 shows the regression result obtained from natural soils, and the curve of REA1 shows the regression result obtained from artificially mixed soils. Mikasa's curve is located at the middle of the two curves of REN4 and REA1 by the authors.

\section{On sensitivity ratio}

Fig. 10 shows the relationship between the sensitivity ratio $S_{t}$ and the liquidity index $I_{L}$, which Mikasa (1967) compared to the data measured in Osaka clay with the curves found 


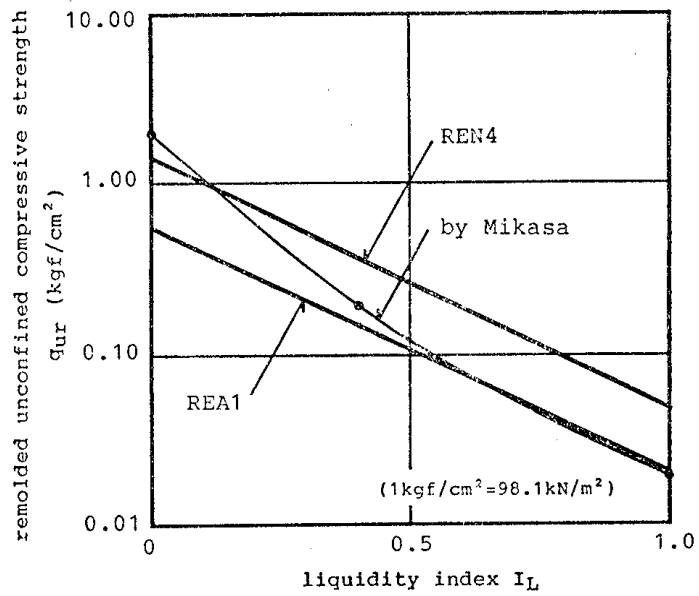

Fig. 9. Regression curves and Mikasa's standard curve for $\boldsymbol{q}_{u r}-\boldsymbol{I}_{L}$ relationship

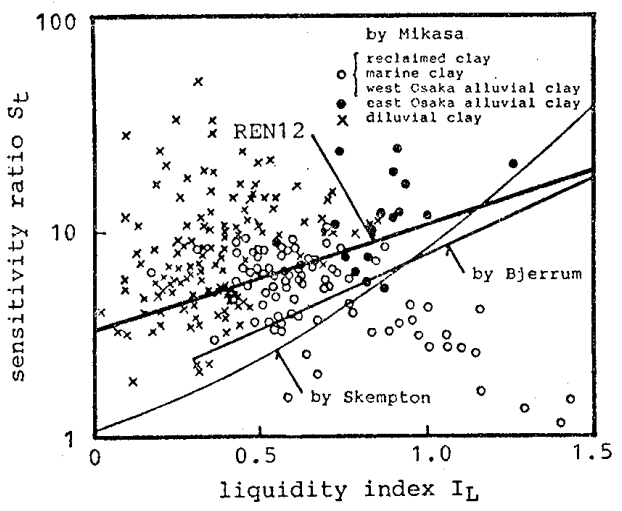

Fig. 10. Regression curves for $S_{t}-I_{L}$ relationship

by Skempton (1953) and by Bjerrum (1954). The curve of REN12 by the authors is also illustrated in this figure. As shown in this figure, the curve of REN12 is found to increase directly with increasing $I_{L}$, as same trend as those curves by Skempton and by Bjerrum, and also locates almost above those curves.

\section{On Compression index}

i) The relationship between the compression index and the liquid limit

Skempton (1944) had found Eq. (31) in the relationship between the compression index $C_{c}$ and the liquid limit $w_{L}$, and afterwards Eqs. (32) to (36) were reported for different soft grounds in Japan. Fig. 11 shows the curves of these formula obtained in the past and the curves of REN17 and REN19 obtained

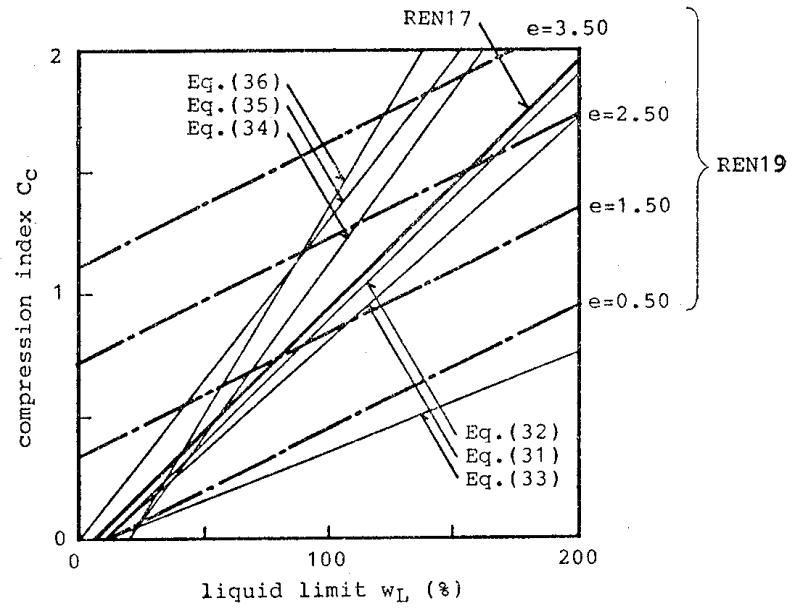

Fig. 11. Regression curves for $C_{c}-w_{L}$ relationship

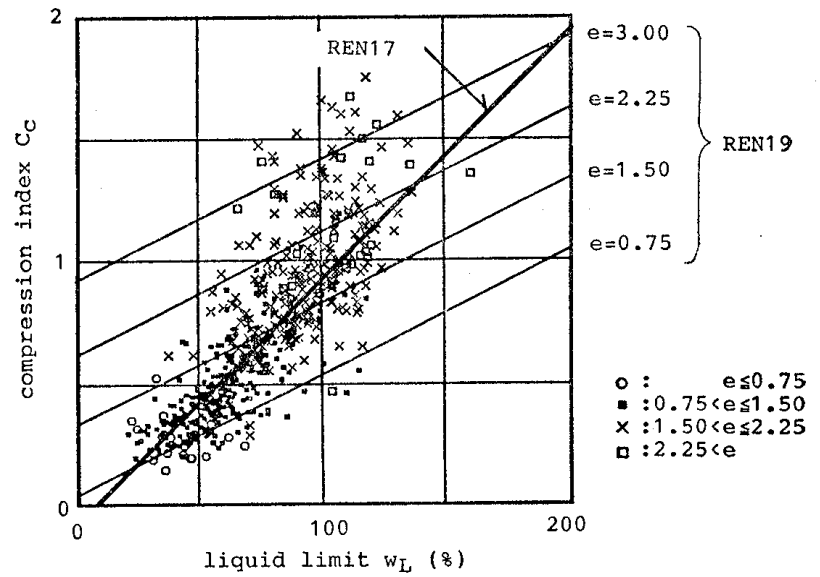

Fig. 12. Measured data and regression curves for $C_{c}-w_{L}$ relationship

by the authors. The curve of REN17 shows the regression result of analyzing $C_{c}$ with only $w_{L}$ as well as the regression result in the past. The curve of REN19 shows the multiple regression result of analyzing $C_{c}$ with both $w_{L}$ and the void ratio $e$.

As shown in this figure, the curve of REN17 is necessarily close to the curve of Eq. (32) for Osaka alluvial clay, and is also close to the curve of Eq. (31) by Skempton. But each curve of Eqs. (33) to (36) has a distinct tendency. This means that the factors of density and water content of the soil expressed in Eq. (4) are not taken into account in the regression analysis.

REN19 is analyzed by using the independent variable $e$ characterizing soil density in addition to $w_{L}$. The curves of REN19 can 
describe approximately the curves of Eqs. (31) to (36) and others reported in the past, by varying the values of the parameter $e$ of REN19 based on the measured data in Osaka and Hyogo (Fig. 12). This means that the multiple regression analysis presented here is valid.

Skempton (1944)

$$
C_{c}=0.009\left(w_{L}-10\right)
$$

Osaka alluvial clay (Murayama, Akai and Ueshita, 1958)

$$
C_{c}=0.01\left(w_{L}-12\right)
$$

Rumoi clay (Taniguchi, 1962)

$$
C_{c}=0.004\left(w_{L}-10\right)
$$

Ishikari clay (Taniguchi, Abe and Goto, 1960)

$$
C_{c}=0.014\left(w_{L}-20\right)
$$

Ariake clay (Kyushu Branch of JSSMFE, 1959)

$$
C_{c}=0.013 w_{L}
$$

Nagoya clay (Tokai Branch of AIJ, Chubu Branch of JSSMFE and the Society for Research in Nagoya Ground, 1969)

$$
C_{c}=0.017\left(w_{L}-20\right)
$$

ii) The relationship between the compression index and the void ratio

Eqs. (37) to (44) show the relationships between the compression index $C_{c}$ and the void ratio $e$ which are reported for different soft

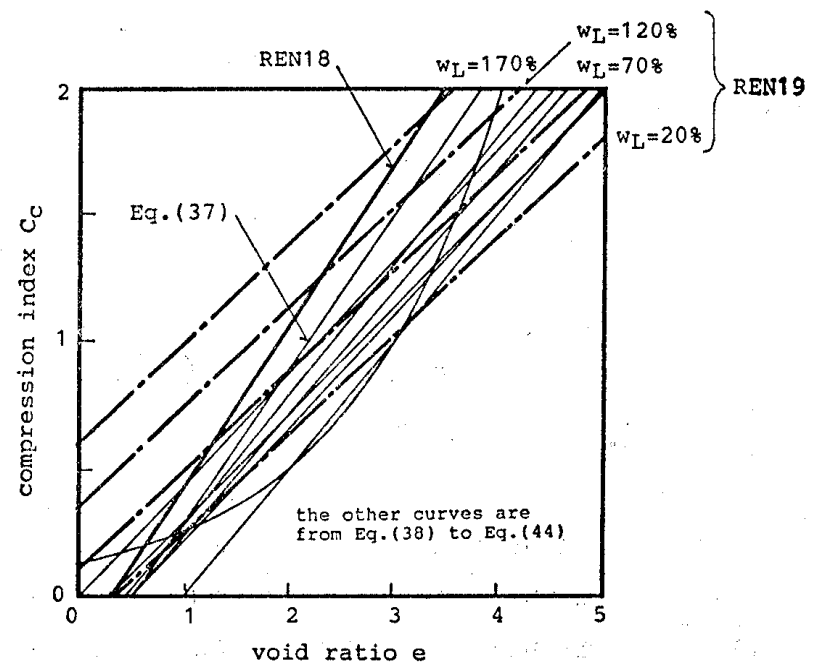

Fig. 13. Regression curves for $C_{c}-e$ relationship grounds in Japan. Fig. 13 shows the curves of these formula and the curves of REN18 and REN19 obtained by the authors. REN18 is the regression result of analyzing $C_{c}$ with only $e$, and REN19 is the multiple regression result of analyzing $C_{c}$ with both $e$ and $w_{L}$. As shown in this figure, the curve of REN18 is necessarily close to the curve of Eq. (37) for Osaka alluvial clay. The curves of Eqs. (37) to (44), however, have distinct tendencies to each other, because they lack a factor characterizing the soil types as expressed in Eq. (4).

The curves of REN19 can describe approximately the curves reported in the past by varying the value of parameter $w_{L}$ of REN19. This means that the multiple regression analysis presented here is valid.

Osaka alluvial clay (Murayama, Ueshita and Shibata, 1960)

$$
C_{c}=0.6(e-0.5)
$$

Ariake clay (Kyushu Branch of JSSMFE, 1959)

$$
C_{c}=0.48(e-0.50)
$$

Ariake Ohmuta clay (Uchida and Matumoto, 1959)

$$
e=3.0+3.4 \log C_{c}
$$

Chikuho Iizuka clay (Uchida and Matumoto, 1960)

$$
C_{c}=0.42(e-0.30)
$$

Lake Biwa organic soil (Kinoshita, Horata and Taniyama, 1960)

$$
C_{c}=0.44 e
$$

Hachirogata clay(Fujita, Kudara and Harada, 1960)

$$
C_{c}=0.44(e-0.5)
$$

Ohgaki clay (Japan Highway Public Co., 1963)

$$
C_{c}=0.51 e-0.23
$$

Kushiro clay (Maeguchi, Sakai and Oyamada, 1965)

$$
e=2 C_{c}+1.0
$$

Examination of the Multiple Regression Equation

On unconfined compressive strength

Comparing REN1 to REN3 with REN4 to 
REN6 in Table 4, which represent the results of analyzing $q_{u}$ and $q_{u r}$ respectively of natural soils, the multiple correlation coefficients $R$ of $q_{u r}$ are found to be larger than those of $q_{u}$, in both regression models 1 and 2 . This means that the characteristics of $q_{u}$ include one more factor of soil structure which is significantly included in the factor of sensitivity ratio $S_{t}$ than those of $q_{u r}$ as shown in ihe following equation.

$$
q_{u}=S_{t} q_{u r}
$$

Comparing REN4 to REN6 in Table 4 with REA1 to REA4 in Table 14, which represent the results of analyzing $q_{u r}$ of natural soils and artificially mixed soils respectively, it is found that $R$ of $q_{u r}$ for artificially mixed soils is larger than that of $q_{u r}$ for natural soils. In Fig. 9, the curve of REA1 of $q_{u r}$ for artificially mixed soils is located below the curve of REN4 of $q_{u r}$ for natural soils. This means that there is difference in soil structure between artificially mixed soils and natural soils.

\section{i) The regression model 1}

As shown in REN2 and REN5 in Table 4 and in REA2 in Table 14, the absolute value of the partial correlation coefficient $r(=0.012)$ of $e$ for artificially mixed soils is smaller than those of $r(=-0.371,-0.439)$ for the natural soils. Referring to the shifts of $F$-values during the analysis in Table 15, if the authors include $e / w_{L}$ in the regression equation, the partial correlation coefficient $r(=-0.755)$ of $e / w_{L}$ indicates a high absolute value. This means that the independent variable $X_{1}$ of Eq. (16) should be $e$ for natural soils and $e / w_{L}$ for artificially mixed soils.

Table 19 shows the predicted values of $q_{u}$ and $q_{u r}$ at the plastic and liquid limits, which are obtained by substituting $I_{L}=0$ and $I_{L}=1$

Table 19. Predicted $q_{u p}$ and $q_{u L}\left(\mathrm{kgf} / \mathrm{cm}^{2}\right)$

\begin{tabular}{l|l|l}
\hline & $q_{u p}$ & $q_{u L}$ \\
\hline REN 1 & 4.289 & 0.566 \\
\hline REN 4 & 1.456 & 0.051 \\
\hline REA 1 & 0.568 & 0.022 \\
\hline \multicolumn{2}{|c}{$\quad\left(1 \mathrm{kgf} / \mathrm{cm}^{2}=98.1 \mathrm{kN} / \mathrm{m}^{2}\right)$}
\end{tabular}

to the single regression equations of REN1, REN4 and REA1. As shown in this table, predicted values of $q_{u}$ and $q_{u r}$ at the plastic and liquid limits become smaller in descending order as follows : $q_{u}$ of natural soils (REN1), $q_{u r}$ of natural soils (REN4), $q_{u r}$ of artificially mixed soils (REA1). This order is correlated with soil structure.

\section{ii) The regression model 2}

Reviewing the $F$-values shown in the 2nd step in Table 6 or 8 , the plastic limit $w_{p}$ can account mainly for the variable $X_{2}$ in Eq. (22).

Referring to the partial correlation coefficient $r$ of REN3, REN6 and REA3, $e / w_{L}$ can contribute to characterizing $q_{u}$ or $q_{u r}$ much more than $w_{p}$ or $1 / w_{L}$.

Table 20 shows the values of $M, \Gamma$ and $\lambda$ that are obtained by the regression analysis of Eq. (19). As shown in this table, the variations of coefficients of physical properties which explain $M, \Gamma$ and $\lambda$ are small, thus the regression model 2 can be recognized.

\section{On modulus of deformation}

REN9 to REN11 in Table 4 show the analyzed results for the secant modulus of deformation $E_{50}$ (modulus at $q_{u} / 2$ ) of natural soils, and REA6 to REA9 in Table 14 show those for artificially mixed soils. As shown in these tables, the multiple correlation coefficients $R$ of $E_{50}$ or $E_{50 r}$ are high values for both regression models 1 and 2 as well as $R$ of $q_{u}$. This shows that $E_{50}$ or $E_{50 r}$ and $q_{u}$ are correlated strongly to each other. The following regression result $\mathrm{Eq}$. (46) was given by JSSMFE (1966).

$$
E_{50}=28.57 q_{u}-1.14
$$

The authors obtained the following regression result:

$$
\begin{aligned}
E_{50} & =57.26 q_{u}-7.30 \\
n & =764 \quad R=0.863
\end{aligned}
$$

Table 20. M, $\Gamma, \lambda$ of $q_{u}$ or $q_{u r}\left(\mathrm{kgf} / \mathrm{cm}^{2}\right)$

\begin{tabular}{c|c|c|c}
\hline & $M$ & $\Gamma$ & $\lambda$ \\
\hline REN 3 & $3.114 \cdot \exp \left(0.039 w_{p}\right)$ & 0.511 & $0.006 w_{L}$ \\
\hline REN 6 & $1.836 \cdot \exp \left(0.033 w_{p}\right)$ & 0.444 & $0.004 w_{L}$ \\
\hline REA 4 & $2.606 \cdot \exp \left(0.030 w_{p}\right)$ & 0.351 & $0.004 w_{L}$ \\
\hline \multicolumn{2}{|c}{$\left(1 \mathrm{kgf} / \mathrm{cm}^{2}=98.1 \mathrm{kN} / \mathrm{m}^{2}\right)$}
\end{tabular}


The value of $R$ for REN20 is very high. The difference of the partial regression coefficient of $q_{u}$ between Eq. (46) and REN20, may be due to the influence of soil structure.

The theoretical relationship between $E_{50}$ and $q_{u}$ can be obtained as follows. In this study, the strain at failure $\varepsilon_{u}$ of undisturbed soil is nearly constant. The value of $\varepsilon_{u}$ has the average of $5.03 \%$ and the value of standard deviation is 3.44\%. Assuming $\varepsilon_{u}$ and $\varepsilon_{0}$ as constant, Eq. (47) is obtained.

$$
E_{50}=q_{u} / 2 \varepsilon_{0}=a q_{u}
$$

where $\varepsilon_{0}:$ strain at $q_{u} / 2$

$$
a \text { : constant }\left(=1 / 2 \varepsilon_{0}\right)
$$

Accordingly, the strong correlation between $q_{u}$ and $E_{50}$ can be explained, and the form of linear regressions in both Eq. (46) and REN20 can also be proved.

Table 21 shows the predicted values of $E_{50}$ and $E_{50 r}$ at plastic and liquid limits, and Table 22 shows the predicted values of $M$, $\Gamma, \lambda$. As shown in these tables, both the influence of soil structure and the stability of the regression equation will be as same as in case of $q_{u}$.

\section{On consolidation yield stress}

As shown in REN14 to REN16 in Table 4, the multiple correlation coefficients $R$ show large values for both regression models 1 and 2 , as also in case of $q_{u}$. This means that a correlation between $q_{u}$ and $p_{c}$ exists as expressed by Eq. (17), and the value of $M$ in this Eq. (17) is said to be a constant of approximately 0.3 (Mikasa, Nishigaki and Okajima, 1978; Nakase and Kamei, 1988).

Table 21. Predicted $E_{50 p}$ and $E_{50 L}\left(\mathrm{kgf} / \mathrm{cm}^{2}\right)$

\begin{tabular}{c|c|c}
\hline & $E_{50 p}$ & $E_{50 L}$ \\
\hline REN 9 & 234.628 & 22.109 \\
\hline REA 6 & 5.760 & 0.348 \\
\hline
\end{tabular}

Table 22. M, $\Gamma, \lambda$ of $E_{50}$ or $E_{50 r}\left(\mathrm{kgf} / \mathrm{cm}^{2}\right)$

\begin{tabular}{l|c|c|c}
\hline & $M$ & $\Gamma$ & $\lambda$ \\
\hline REN 11 & $285.431 \cdot \exp \left(0.033 w_{p}\right)$ & 0.304 & $0.006 w_{L}$ \\
\hline REA 9 & $83.013 \cdot \exp \left(0.013 w_{p}\right)$ & 0.214 & $0.004 w_{L}$ \\
\hline
\end{tabular}

$\left(1 \mathrm{kgf} / \mathrm{cm}^{2}=98.1 \mathrm{kN} / \mathrm{m}^{2}\right)$
For some references, Table 23 shows the predicted values of $p_{c}$ at plastic and liquid limits from regression model 1 , and Table 24 shows the predicted values of $M, \Gamma$ and $\lambda$ from regression model 2 .

\section{On sensitivity ratio}

As shown by the low multiple correlation coefficients $R(=0.460,0.494)$ in REN12 and REN13 in Table 4 or by the wide scattering plots in Fig. 14, the correlation between $S_{t}$ and $I_{L}$ is weak. Therefore it is proved quantitatively that sensitivity ratio or soil structure is almost independent of types, density and water content of soil.

In future, it would be necessary to analyze $S_{t}$ by the factors of the geohistory or chemical properties which are not treated in this paper.

\section{On internal friction angle}

Internal friction angle $\left(\phi_{u}\right)$ in this paper is determined by undrained triaxial compression test. REN7 in Table 4 shows that the multiple

Table 23. Predicted $\boldsymbol{p}_{c p}$ and $\boldsymbol{p}_{c L}\left(\mathrm{kgf} / \mathrm{cm}^{2}\right)$

\begin{tabular}{c|c|c}
\hline & $p_{c p}$ & $p_{c L}$ \\
\hline $\operatorname{REN~14}$ & 9.043 & 1.418 \\
\hline
\end{tabular}

Table 24. M, $\Gamma, \lambda$ of $p_{c}\left(\mathrm{kgf} / \mathrm{cm}^{2}\right)$

\begin{tabular}{c|c|c|c}
\hline & $M$ & $\Gamma$ & $\lambda$ \\
\hline REN 16 & $4.894 \cdot \exp \left(0.047 w_{p}\right)$ & 0.676 & $0.006 w_{L}$ \\
\hline
\end{tabular}

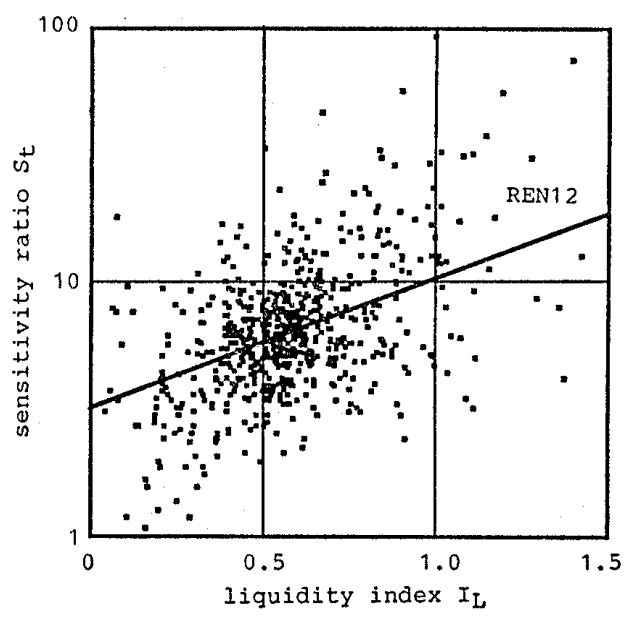

Fig. 14. Measured data and regression curve for $S_{t}-I_{L}$ relationship 
correlation coefficient $R(=0.267)$ is small for the cohesive soils of which the clay content is more than $20 \%$, but the authors obtained high value of $R$ for the cohesive soil composed of much sand and gravel (Yao, Hirata and Saito, 1985a).

As a result, in Tables 4 and 14 the multiple correlation coefficients $R$ show large values for $q_{u}, q_{u r}, \varepsilon_{u r}, E_{50}, E_{50 r}, p_{c}$ and $C_{c}$, but show small values for $\varepsilon_{u}$ and $\phi_{u}$.

\section{Comparison of the Two Regression Models}

In order to examine the relationship between each independent variable in regression models 1 and 2 and to ensure that the regression models 1 and 2 are essentially the same model, the following examination was carried out.

In the case of $q_{u}$ or $q_{u r}$ of natural soils, as shown in Table 6 or Table 8 , an $F$-value of $I_{L}$ is the highest in the Initiation state, that is, $I_{L}$ is the most suitable independent variable. But at the 1st step, $F$-value of $I_{L}$ reduces suddenly, if $e / w_{L}$ is included in the regression equation. This means that there is a strong correlation between $I_{L}$ and $e / w_{L}$. This correlation is explained as follows.

$$
\begin{aligned}
I_{L} & =\left(w-w_{p}\right) /\left(w_{L}-w_{p}\right) \\
& =\left(w-w_{p}\right) / I_{p}=w / I_{p}-w_{p} / I_{p}
\end{aligned}
$$

Assuming $I_{p}=a w_{L}$, because of the strong correlation between $I_{p}$ and $w_{L}$ (Hirata, 1985).

$$
I_{L}=w / a w_{L}-w_{p} / a w_{L}
$$

Assuming $w_{p}=b w_{L}$, because of the strong correlation between $w_{p}$ and $w_{L}$ (Hirata, 1985).

$$
I_{L}=w / a w_{L}-b w_{L} / a w_{L}=A w / w_{L}-B
$$

where $A=1 / a, B=b / a=b A$

By using the relationship $w=S_{r} e / G_{s}$,

$$
I_{L}=A S_{r} e / G_{s} w_{L}-B
$$

Considering specific gravity $G_{s}$ is approximately constant of 2.65, the following Eq. (48) is obtained.

$$
I_{L}=A^{\prime} S_{r} e / w_{L}-B
$$

where $A^{\prime}=A / 2.65$

Assuming $\mathrm{S}_{r}=100 \%$ as a fully saturated soil, Eq. (49) is obtained.

$$
I_{L}=A^{\prime} e / w_{L}-B
$$

Thus, in case of natural soils, the relationship between $I_{L}$ and $e / w_{L}$ is proved to be dependent as shown by Eq. (49). Therefore in Tables 6 and 8 , it can be understood that the $F$-value of $I_{L}$ become very small at the 1st step, where $e / w_{L}$ has already been included in the regression equation. Further, as shown in Table 4, the predictive accuracy of regression model 2 of which the independent variables are $1 / w_{L}$ and $w_{p}$ in addition to $e / w_{L}$, could be understood to be necessarily higher than those by model 1 .

\section{CONCLUSIONS}

In this paper, the relationships between a mechanical property and some physical properties were studied by employing the multiple regression analysis for both natural and artificially mixed cohesive soils. The following conclusions were obtained:

(1) The regression models 1 and 2 proposed herein were proved to be valid for predicting shear strength of cohesive soils by examining $F$-values on analysis procedures and multiple correlation coefficients $R$ of analysis results. These models were also valid for predicting modulus of deformation $E_{50}$, consolidation yield stress $p_{c}$, etc., because of their strong correlations with shear strength.

(2) The validity of the concept that the mechanical property is characterized by the soil types and states, can be quantitatively proved by performing the multiple regression analysis proposed herein.

(3) By examining the shifts of $F$-value on analysis procedure, mutual relationships between each physical property to explain a mechanical property can be understood and made clear. The dependent relationship between the regression models 1 and 2 in the fully saturated case was proved by both regression analysis and theoretical examination.

(4) The regresssion equations of unconfined compressive strength $q_{u}$, modulus of deformation $E_{50}$, consolidation yield stress $p_{c}$ and compression index $C_{c}$ were obtained with high predictive accuracy. 


\section{NOTATION}

$$
\begin{aligned}
& A_{c}=\text { activity } \\
& C=\text { clay content } \\
& C_{c}=\text { compression index } \\
& c_{u}=\text { cohesion } \\
& c_{u L}=c_{u} \text { at liquid limit } \\
& c_{u p}=c_{u} \text { at plastic limit } \\
& c_{u r}=c_{u} \text { at remolded state } \\
& D_{\max }=\text { maximum grain size } \\
& D_{10}=\text { effective grain size } \\
& e=\text { void ratio } \\
& E_{50}=\text { secant modulus of deformation at } q_{u} / 2 \\
& E_{50 L}=E_{50} \text { at liquid limit } \\
& E_{50 p}=E_{50} \text { at plastic limit } \\
& E_{50 r}=E_{50} \text { at remolded state } \\
& I_{f}=\text { flow index } \\
& I_{L}=\text { liquidity index } \\
& I_{p}=\text { plasticity index } \\
& M=\text { slope of critical state line when it is pro- } \\
& \text { jected on to a constant volume plane } \\
& M_{0}=\text { silt content } \\
& N=\text { number of blows of liquid limittest } \\
& n=\text { total number of data samples } \\
& p_{c}=\text { consolidation yield stress } \\
& p_{c L}=p_{c} \text { at liquid limit } \\
& p_{c} p=p_{c} \text { at plastic limit } \\
& P_{r}=\text { plasticity ratio }\left(=I_{p} / w_{p}\right) \\
& q_{u}=\text { unconfined compressive strength } \\
& q_{u L}=q_{u} \text { at liquid limit } \\
& q_{u p}=q_{u} \text { at plastic limit } \\
& q_{u r}=\text { remolded unconfined compressive strength } \\
& R=\text { multiple correlation coefficient } \\
& r=\text { partial correlation coefficient } \\
& S=\text { sand content } \\
& S_{r}=\text { degree of saturation } \\
& S_{t}=\text { sensitivity ratio } \\
& T=\text { correcting coefficient of Eq. (28) } \\
& U_{c}=\text { uniformity coefficient } \\
& U_{c}^{\prime}=\text { coefficient of curvature } \\
& w=\text { water content } \\
& w_{L}=\text { liquid limit } \\
& w_{L t}=\text { measured liquid limit } \\
& w_{p}=\text { plastic limit } \\
& w_{p_{t}}=\text { measured plastic limit } \\
& \Gamma=\text { void ratio of soil at critical state } \\
& \gamma_{t}=\text { unit weight } \\
& \varepsilon_{0}=\text { strain at } q_{u} / 2 \\
& \varepsilon_{u}=\text { failure strain } \\
& \varepsilon_{u r}=\varepsilon_{u} \text { at remolded state } \\
& \lambda=\text { slope of normal consolidation line } \\
& \phi_{u}=\text { undrained internal friction angle }
\end{aligned}
$$

\section{REFERENCES}

1) Bjerrum, L. (1954): "Geotechnical properties of Norwegian clay," Géotechnique, Vol. 4, No. 2, pp. 49-69.

2) Bjerrum, L. and Simons, N. E. (1960): "Comparison of shear strength characteristics of Normally consolidated clay," Proc. ASCE Research Conf. on Shear Strength of Cohesive Soils, pp. 711-726.

3) Flury, B. and Riedwyl, H. (1988): Multivariate Statistics (A Practical Approach), Chapman and Hall Ltd., London.

4) Fujita, N., Kudara, T. and Harada, S. (1960): "Testing levee in Hachirogata reclamation," Tsuchi-to-Kiso, JSSMFE, No. 42, pp. 4-17 (in Japanese).

5) Hirata, S. (1985): "Mechanical characteristics of ground materials," Thesis presented to Kansai University for the Degree of Master of Engineering (in Japanese).

6) Japan Highway Public Co. (1963): 4th Report on Measured Results of Test Embankments in Improvement of Soft Ground at Ohgaki Division of Meishin Express Way (in Japanese).

7) JSSMFE (1966): Survey, Design and Construction for Soft Ground, Library on Soil Mechanics and Foundation Engineering, Vol. 1 (in Japanese).

8) JSSMFE (1979): Soil Testing Manual (in Japanese).

9) Kinoshita, S., Horata, N. and Taniyama, S. (1960): "Engineering properties of Lake Biwa organic soils," Tsuchi-to-Kiso, JSSMFE, No. 40, pp. 4-10 (in Japanese).

10) Kobayashi, R. (1982): Introduction to Method of Correlation and Regression Analysis, JUSE. Press Ltd. (in Japanese).

11) Kyushu Branch of JSSMFE (1959): "Soil properties in Ariake sea shore," Tsuchi-to-Kiso, JSSMFE, No. 34, pp. 31-36 (in Japanese).

12) Maeguchi, S., Sakai, K. and Oyamada, H. (1965): "Soil investigation at site of Kushiro thermal power plant," Tsuchi-to-Kiso, JSSMFE, Vol. 13, No. 8, pp. 3-9 (in Japanese).

13) Mikasa, M. (1964): "Classification of engineering properties of soils and it's meaning," Tsuchito-Kiso, JSSMFE, Vol. 12, No. 4, pp. 17-24 (in Japanese).

14) Mikasa, M. (1967): "Conditional chart of cohesive soils," Proc. 20th Annual Meeting of JSCE, III, pp. 60-1-60-4 (in Japanese).

15) Mikasa, M., Nishigaki, $Y$. and Okajima, $Y$. (1978): "Comparison to $c_{u} / p$ values with several 
testing methods," Proc. 13rd Annual Meeting of JSSMFE, D6, pp. 325-328 (in Japanese).

16) Murayama, S., Akai, K. and Ueshita, K. (1958): "Engineering properties of Osaka diluvial clay," Tsuchi-to-Kiso, JSSMFE, No. 28, pp. 39-47 (in Japanese).

17) Murayama, S., Ueshita, K. and Shibata, T. (1960): "Mechanical properties of Osaka alluvial clay and it's countermeasure," Tsuchi-to-Kiso, JSSMFE, No. 2, pp. 26-32 (in Japanese).

18) Nakase, A. and Kamei, T. (1988): "Undrained shear strength of remoulded marine clays," Soils and Foundations, Vol. 28, No. 1, pp. 29-40.

19) Ohsaki, Y. (1961): Foundation Engineering (theory and practice), Corona Publishing Co., Ltd. (in Japanese).

20) Roscoe, K.H., Schofield, A.N. and Thurairajah, A. (1963): "Yielding of clays in states wetter than critical," Géotechnique, Vol. 13, No. 3, pp. 211-240.

21) Skempton, A. W. (1944): "Notes on the compressibility of clays," Quart. Jour. Geol. Soc., London, Vol. C, pp. 119-125.

22) Skempton, A.W.(1953): "The colloidal "activity" of clays," Proc. 3rd. Int. Conf. on SMFE., Vol. 1.

23) Taniguchi, H., Abe, T. and Goto, M. (1960): "Engineering properties of basement clay in
Ishikari peat layer," 5th Engineering Symposium of Hokkaido Developement Bureau (in Japanese).

24) Taniguchi, H. (1962): "Engineering properties of basement clay in Rumoi harbor," Tsuch-toKisso, JSSMFE, No. 49, pp. 19-27 (in Japanese).

25) Tokai Branch of AIJ, Chubu Branch of JSSMFE and the Society for Research in Nagoya Ground (1969): Outline of Nagoya Ground, Corona Publishing Co., Ltd. (in Japanese).

26) Uchida, I. and Matumoto, R. (1959): "Soil properties of Ohmuta marine layer," Tsuchi-toKiso, JSSMFE, No. 35, pp. 20-25 (in Japanese).

27) Uchida, I. and Matumoto, R. (1960): "Soft ground at lizuka in Chikuho area and it's cone penetoro mater results", Tsuchi-to-Kiso, JSSMFE, No. 37, pp. 19-26 (in Japanese).

28) Yao, S., Hirata, S. and Saito, C. (1985a): "The relations between mechanical characteristics and physical properties of the ground materials," Summaries of Technical Papers of Annual Meeting of Architectural Institute of Japan, pp. 903-904 (in Japanese).

29) Yao, S., Hirata, S. and Saito, C. (1985b): “The relations between the mechanical characteristics and the grain size composition of soils (Part 3)," Proc. 20th Annual Meeting of JSSMFE, DO, pp. 141-142 (in Japanese). 